\title{
Basic model of resocialization of convicts
}

\author{
Tatiana Vyacheslavna Maltseva ${ }^{1 *}$, Konstantin Borisovich Malyshev ${ }^{2}$, Nikolay Gurgenovich \\ Sobolev $^{2}$, Ekaterina Pavlovna Kirillova ${ }^{3}$, and Alexey Nikolaevich Mikhailov ${ }^{3}$ \\ ${ }^{1}$ Academy of Management of the Russian Ministry of Internal Affairs, Department of Psychology, \\ Pedagogy, and Organization of Work with Personnel, Moscow, Russia \\ ${ }^{2}$ Vologda Institute of Law and Economics of the Federal Penal Service of Russia, Psychological \\ Faculty, Department of Legal Psychology and Pedagogy, Vologda, Russia \\ ${ }^{3}$ Vyatka State University, Faculty of Pedagogy and Psychology, Department of Psychology, Vyatka, \\ Russia
}

\begin{abstract}
Purpose of the study: development of directions and basic model of resocialization of convicts. This study uses a three-factor dichotomous baseline model of convict resocialization with a single "external-internal" dichotomy. This model defines the "vectors of development" of a convict and shows the common factors of this process, which correctional officers need to consider when organizing re-socialization work with this category of people. The research resulted in conclusions from the analysis of three factor-categories of pedagogy: "education", "training" and "education", determining the objective (external) position of the individual, and "selflearning" and "self-education", determining the subjective (internal) position of the individual. While using the principle of "semantic proximity", a three-factor basic-dichotomous "superimposition" of these factors-categories of pedagogy on such concepts as "values", "activity", "intellect" has been performed. This "superposition" results in three combined basic psycho-pedagogical factors ("value education", "active learning", "intellectual education"). From this model, it becomes clear what direction correctional officers should work in terms of "developing the consciousness" of the convict, given the factors in question. The novelty of the study is that the work shows specific examples of activities performed by the staff with convicts, which are associated with the implementation of these factors and the impact on the process of resocialization.
\end{abstract}

Keywords: personality, administration of justice, enforcement of the law, prisoners, crime prevention, education in correctional institutions

\section{Introduction}

One of the current problems is the resocialization of convicts. Resocialization of convicts implies a process of adaptation and restoration of skills to enter society after release from punishment. This is a system of rehabilitative measures to restore social functions weakened or lost while serving a criminal sentence and the status of the individual.

\footnotetext{
* Corresponding author: mtv-psy@mail.ru
} 
With the help of the staff and the environment of the penitentiary institution (PI) there is an external "objective impact" on the convict's consciousness, which will then form his/her internal "subject position" (when the convict will "inside himself/herself" reflect his/her individual "value-based" goals, will regulate his/her "activity" with the help of his/her found methods and in the end will implement with the help of his/her adaptive intelligence the goals of adaptive self-development [1-5].

Based on the assumption that it is impossible to change "circumstances", then the attitude toward them shall be changed. "Circumstances" of a convict's incarceration cannot be changed, but one can and shall "adapt" and form one's "subjective position of selfdevelopment" in doing so. To do this, it is necessary to organize the work of penitentiary teachers, psychologists, and psychiatrists in such a way that, with the help of their reflection of the problems of the convict in the sphere of the developing "space" (S) of the prison environment, the regulation of relations between employees and convicts in the developing environment of the prison that require "energy" (E) costs, so to implement effective methods of psychotherapy for the convict within a certain "time" $(\mathrm{T})$ and achieve positive results in this process. As a result, an "informational development" will be formed for the convict and will have a positive effect on his/her future re-socialization [6-9].

This unified substrate concept emerged by using the principle of "semantic proximity" and by "superimposing" two three-dimensional bases: 1) "information" (space, energy, time) and 2) "development" (upbringing, training, education). The substrate concept-category of "information" relies on the "physical" postulate of Ganzen-Malyshev: "Any 'information' about the surrounding reality can be described by 'spatial', 'energy' and 'temporal' characteristics" [10]. These concepts ("space", "energy" and "time") form a three-factor basis of "physical categories - factors" for "information" with a single generalized dichotomy "external - internal". The substrate unified physical and pedagogical concept of "informational development" will be connected with such basic concepts as "space of education", "energy of learning", "time of education". The strategy of "coercive force" and the influence on the mind of the convict as an "object" of influence does not lead to anything but anger, and the process of "resocialization" of the convict slows down and has a "slippage" in terms of educational impact on his/her consciousness.

\section{Methods}

The work uses a three-factor basic model of the "development" of a convict in isolation, with a single dichotomy of "external - internal" in relation to the three categories-factors of pedagogy:

1) Mentoring $(0 \mathrm{X}(+))$ is reflected in the social sphere of space $(\mathrm{S})$ of the individual,

2) Learning $(0 \mathrm{Y}(+))$ is regulated in the social sphere by the energetic (E) costs of individuality,

3) Education $(0 \mathrm{Z}(+))$ is realized in the social sphere during the time $(\mathrm{T})$ of the subject's life.

This is seen as the object (external)position of the individual.

1) Self-mentoring $(0 \mathrm{X}(-))$ is reflected in the individual sphere of space $(\mathrm{P})$ of the individual,

2) self-learning $(0 \mathrm{Y}(-))$ is regulated in the individual sphere at the expense of the energy (E) cost of individuality,

3 ) self-education $(0 Z)(-))$ is realized in the individual sphere during the time $(\mathrm{T})$ of the subject's life.

This is the subjective(internal) position of the individual, where Space, Energy, Time are the three-factor basis of information with the generalized single dichotomy "external internal"), where reflection, regulation, realization are the three-factor basis of the main 
functions of the psyche with the generalized single dichotomy of "external - internal") [11, $12]$.

In this case, there is a "superposition" of three three-factor bases with a single generalized dichotomy "external - internal" (the basis-factors of "pedagogy", the basis-factors of basic "functions of mentality" and the basis-factors of "information" - F(1), F(2), F(3)) (see Figure 1).

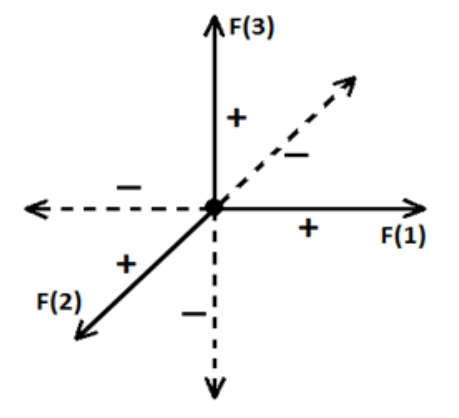

Fig. 1. Three-factor basis with a single generalized dichotomy "external(+) - internal(-)"

The triple of factor-vectors $F(1), F(2), F(3)$ proved to be the optimal dimensionality among other dimensions of bases, which are used in multifactor basis-dichotomous modeling of information in solving the above research problem. The examples display the generalized regularity in the analysis of the three principles manifested in the three-factor basic dichotomous structures, namely, "the principle of nature-expediency", "the principle of culture-technology-expediency" and "the principle of socio-expediency" [13].

\section{Results}

As theoretical analysis has shown, the "perceptual consciousness" of the convict as a developmental "subject" is related to three basic "vectors" - perceptions, namely, "affect", "will", and "thinking". Using the principle of "semantic proximity", it is possible to make a three-dimensional basic "overlay" of these three concepts on such concepts as "values", "activity", and "intellect".

The notions of "attitude", "mapping", "transformation" form a three-factor basis, which can be put in mutual and unambiguous correspondence with a three-factor basis of basic functions of psyche ("reflection", "regulation", "realization") on the basis of the principle of semantic proximity with a single generalized dichotomy of "external-internal".

The result is three combined basic concepts (as a result of "superimposing" the bases) ("affective values", "volitional activity", "thinking intelligence"). The model of "perceptual abilities" of the "subject personality" intellect, obtained as a result of "superposition" of two bases ("subject" and "personality") results in the following basic concept-factors: "affective temperament", "volitional character", "thought orientation" with a single unified dichotomy of "external social" - "internal individual". In managing people, the "subjective personality" of the manager manifests "external social intelligence", and when solving some tasks of the "subjective personality" of the manager, more "internal individual intelligence" manifests itself. In this case, the role of the manager is played by the employee of the correctional facility [14].

The transformation of a convict's "value profile" can occur due to external influence from the staff, the correctional facility's developmental environment, and the convict 
himself/herself on all three of his/her basic "vectors" of consciousness (affect, will, and thinking) when forming his/her "object position":

This trio of "values" forms a three-dimensional basis with a single personal dichotomy of "social-individual". A change in the three-factor basis of the "value attitude" of a convict with three components (affective, behavioral, cognitive) is a necessary but far from sufficient condition for the formation of a developing "objective position" that then passes into a developing "subjective position" of a convict. The presence of three factors ("values", "activity", "intellect") will determine the necessary and sufficient conditions for the formation of a three-dimensional basis for the development of the "subjective personality" consciousness of a convict with a single unified dichotomy of the "external social" - "internal individual". This is very important for the formation of a three-dimensional basic of "subjectdevelopmental strategy" of the convict, which will further ensure effective and successful "developmental resocialization" after release [3].

This result can be formulated as a theorem: "For effective "developmental resocialization" of a convict's personality it is necessary and sufficient to have external (from employees on the convict) and internal (from the convict on himself/herself) influence on convicts' consciousness in the direction of "values", "activity" and "intellect" [15].

\section{Discussion}

It turns out that the external object influence in correctional institutions (on the part of the staff and the developmental environment of correctional institutions) initiates the formation of an internal subjective position of consciousness on the part of the convict. This is the dialectics of formation of the released person's resocialization due to the development of the internal subjective position of the convict, which is influenced by the external objective influence of the staff and the developing environment of the correctional institution during the period of serving the sentence). The first law of dialectics (unity and struggle of opposites) is observed: "the unity and struggle of the objective (external) and subjective (internal) position of the consciousness of the convict in the penitentiary institution. The resolution of this dialectical contradiction of opposing positions in the mind of a convict forms his or her "developmental resocialization" in the future after release. This is the main point of the convict's "correction" in the correctional facility.

The presented combined three-factor basic model of the "development of consciousness" of the convict results in "bringing up values", "teaching in activities", "educating through the intellect" [10].

\section{Conclusion}

Thus, in terms of the "development of the consciousness" of a convict, one must work within these three combined basic psychological and pedagogical factors (value-based education, activity-based learning, intellectual education). The pedagogical "appeals" and "wishes" for the resocialization of the convict in the activity of the Russian Federal Penitentiary Service can be put into practice on the basis of the three-factor basic model of "consciousness development" that is a program "navigator" of the work, which shows in what direction the staff of correctional institutions should build a methodology of external influence on the mind of a convict to organize the "developing environment of correctional institutions". A "coercive-suppressive strategy" of influencing the minds of convicts by correctional facility staff embitters rather than corrects them and impedes their further re-socialization. It is probably possible to use the positive experience in this direction in organizing such "development work" in colonies and prisons abroad. 
Our three-factor baseline measurement approach did not use the possibility of "measurability", i.e., creating an assessment of the three combined baseline psychological and pedagogical factors ("value-based education", "activity learning", "intellectual education") [13]. In the article, of the three factors $F(1), F(2), F(3)$ ("completeness", "orderliness", "measurability") included in the definition of the concept "basis", only the first two factors $(F(1), F(2))$ were used in the study. When evaluating the activities of an institution aimed at the resocialization process of convicts, it is possible to assess the effectiveness and quality of work of a particular institution. In this case, it is necessary to use the possibilities of baseline "measurement", i.e. "realization" of the third factor F(3) in the baseline modeling. This allows to build a baseline measurement technique, which was not done in this study. Solving this problem is beyond the scope of this article.

\section{References}

1. A.N. Andreev, S.I. Artemyeva, Applied Psychology and Pedagogy, 3, 28-38 (2020). https://doi.org/10.1 2737/2500-0543-2020-2838

2. S.A. Borsuchenko, Legal Bulletin of Samara University, 2, 74-79 (2018)

3. E.V. Zautorova, O.B. Panova, N.G. Sobolev, Penitentsiarnaya Nauka, 14(3), 407-414 (2020)

4. E.Yu. Leonova, Fundamental Research, 10-14, 3248-3251. (2013)

5. N.A. Perinskaya, Knowledge. Understanding. Skill. Encyclopedia of the Humanities, 4, 161-162 (2005)

6. V.M. Pozdnyakov, O.V. Volotkevich, Applied Psychology and Pedagogy, 1, 1-20 (2020). https://doi.org/10.12737/2500-0543-2020-1-20

7. A.P. Stoykov, International Scientific Journal "Internauka”, 2(1), 126-127 (2017)

8. C. L. O. Silva, L. A. S. Saraiva, Revista de Administração, 51(4), 366-376 (2016). https://doi.org/10.1016/j.rausp.2016.07.001

9. E.A. Timofeeva, Foreign Prison Experience Resocialization of Prisoners, in SHS Web of Conferences, 62, 12004 (EDP Sciences, 2019)

10. V.V. Kozlov, V.A. Mazilov, V.F. Petrenko, Metodologiya Sovremennoy Psikhologii, 7, 3-6 (2017)

11. K.B. Malyshev, O.A. Malysheva, The methodology of the basic approach in modern psychological research (Vologda-Kursk, 2020)

12. P.K. Anokhin, Nodal questions of the theory of functional systems (Moscow, 1980)

13. K.B. Malyshev, O.A. Malysheva, N.G. Sobolev, Penitentiary Science, 14(1), 105-110 (2020)

14. A.M. Chirkov, Ius Publicumet Privatum, 1(1), 101-105 (2018)

15. L.K. Kairbaeva, Vosstanovitelnoe pravosudie i resocializaciya osuzhdennyh [Restorative Justice and Resocialization of Convicts], Abstract of $\mathrm{PhD}$ thesis in Philosophy (Astana, 2010) 